\title{
Clio
}

Women, Gender, History

37 | 2013

When Medicine Meets Gender

\section{Sexing hormones and materializing gender in Brazil}

\section{Emilia Sanabria}

Translator. Regan Kramer

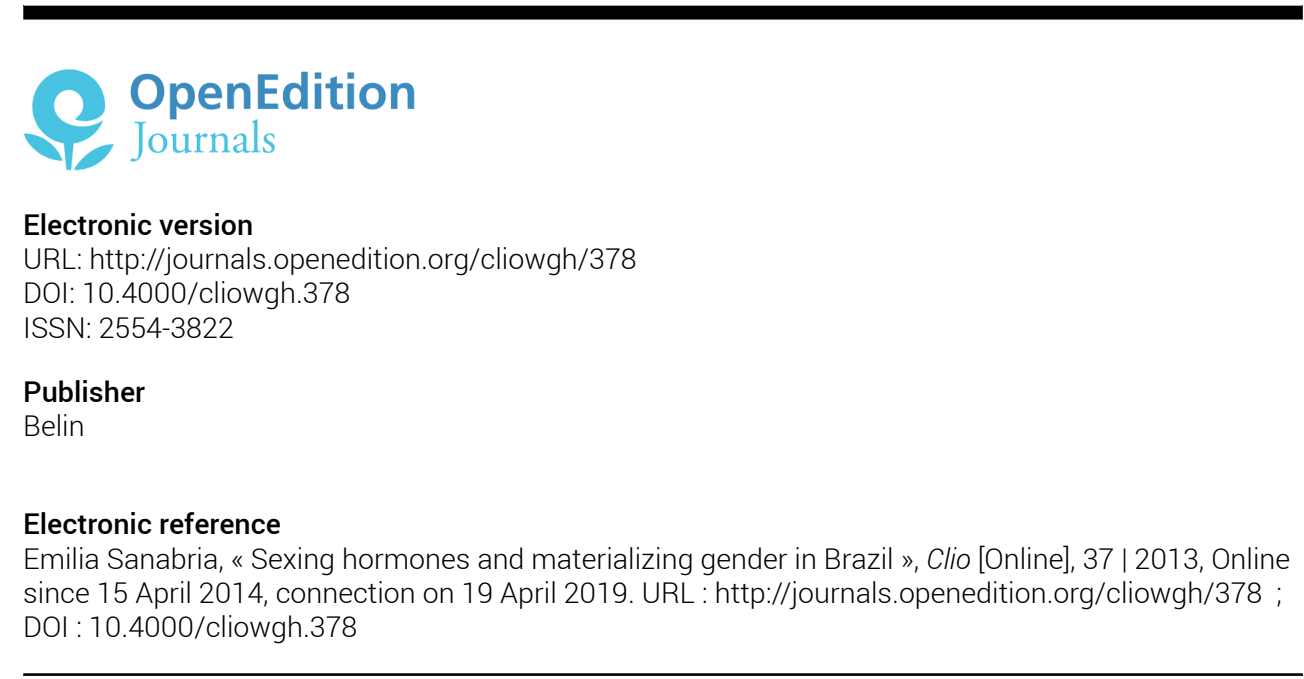

Clio 


\section{Hormones and Reconfiguration of Sexual Identities in Brazil}

The use of hormones is a phenomenon that opens extremely interesting avenues of reflection about the conceptualization of "sex" and "gender." Due to the physiological effects it produces, as well as the discourse that is associated with it, this phenomenon poses the problem of the boundary between the notions of sex and gender. The hormones' action is not limited to their effects on bodily sexual conformity; they also generate different types of social behavior. The present article is based on the work of previous writers on the development of endocrinology ${ }^{1}$ and on my own ethnographic research carried out in Brazil both amongst diverse categories of hormone users and within the medical profession. I conducted extensive interviews with women, gynecologists and travestis ${ }^{2}$ in Salvador. I also did participatory observations in family planning centers, private clinics and a blood-donation center; and I attended three medical conferences, as well as weekly meeting of the Association of travestis ${ }^{3}$ from Bahia. This research allowed me to shed light on the specificity of the Bahian notion of hormônio. First of all,

1 Fausto-Sterling 2000; Oudshoorn 1994.

2 Travesti is an ambiguous identity category that is self-adopted by physiological men who transform their bodies into feminine ones without resorting to genderreassignment surgery. In this article, I refer to them with a feminine pronoun, as that is what they choose to use.

3 This was done between 2005 and 2009 as part of my research for a doctorate on contraceptive choices and both professional and lay conceptions of menstruation. I later did post-doctoral work on local conceptions of the body and of bodily substances. 
the word is used in the singular form there. Many users think of bormônio as a kind of fluid or substance, not unlike blood. This substance is understood to have the capacity to accumulate in the body's cavities, producing growths or swellings. Its circulation reveals that the body is understood to be fairly malleable.

Based on that data, in this article I examine the extent to which my informants' idea of hormônio simply re-inscribes sexual dimorphism, with estrogen emblematizing activities and characteristics of femininity, and testosterone signifying masculinity, and ask whether, in practice, hormônio exceeds such dichotomizations. In this way, I show that the theoretical distinction between "sex" and "gender" in social sciences is called into question by hormonal practices. In this sense, prescribed and informal uses of these pharmacotherapies enact both a troubling of sex/gender and of the distinction between them. This occurs in a highly contested arena, which we might call political.

\section{A critical approach to the history of hormones}

The science historian Nelly Oudshoorn shows that hormones need not have been framed within such a binary model of sex. She argues that the "the chemical model of sex," brought about by early $20^{\text {th- }}$ century developments in endocrinology might have led to a break with the anatomical model of sex, which associated sexual identity with the possession of particular organs. ${ }^{4}$ Nevertheless, the ways in which questions were formulated, as well as the nature of the research conducted in the early $20^{\text {th }}$ century were filled with preconceived notions and were aimed at locating the essence of each sex in an organ or a chemical substance. Yet the new chemical model radically reconfigured the understanding of sex within the life sciences. From that point on, sex circulated throughout the body, and was no longer limited to a specific anatomical area. Quoting from their correspondence, Oudshoorn describes the wonderful puzzlement of early sex hormone researchers when they gradually realized that not only did male hormones occur in female bodies and

4 Oudshoorn 1994: 145. 
female hormones in male bodies, but that estrogens were necessary in emblematically male organisms such as the stallion to enable the androgenizing effects of the male hormones. Without the feminine "substance," these males couldn't masculinize! Oudshoorn shrewdly explains that scientists' disproportionate interest in female sexual hormones was due to the existence of a long-standing gynecological tradition that dichotomized the process of knowledge production around these molecules. Her approach is important because it demonstrates that endocrine sex does not reflect a natural order of things, but was, and indeed continues to be, the product of clinical and experimental practices. The biologist and medical historian Fausto-Sterling goes even further in revealing the extent to which early endocrinologists operated with a heavily gendered understanding of sexual identity. She argues that: "steroid hormones need not have been divided into sex and non-sex categories". 5 Doing so, she argues, has meant that "the signs of gender - from genitalia, to the anatomy of gonads and brains, then to our very body chemistry - [have been integrated] more thoroughly than ever into our bodies". ${ }^{6}$ In this sense, Fausto-Sterling demonstrates that the chemical model of sex actually drove the inscription of gender deeper and more pervasively into the body, not simply locating it in the genital organs or secondary sexual characteristics. The implication of this is two-fold. First it effectively "sexes" the whole body, including behavior and organs such as the brain. Second, it obscures the farreaching non-reproductive and non-sexual effects of steroid hormones by granting excessive attention to their "sexual" characteristics or by sexualizing their non-sex functions (FaustoSterling 2000).

Taking these considerations into account, one can wonder how contemporary uses of hormones express the preceding concerns involving hormones' "sexualizing" action.

\section{Sex becomes exogenous}

5 Fausto-Sterling 2012 [2000]: 28.

$6 \quad$ Ibid. : 147. 
Since the 1950s, hormones have been synthesized and manufactured as pharmaceutical products. This innovation has had powerful concrete implications, because it meant that hormones could circulate, as it were, outside bodies. The radical nature of this possibility undoubtedly explains the fact that the norms and prescription regimens for these substances still massively inscribe their use within a dimorphic model of sex. The question of how hormones are involved in the gendering of bodies dawned on me with particular force during a period of extended fieldwork: shortly before I attended the Congress of the Brazilian Society for Gynecological Endocrinology, which was held in the luxurious Othon Palace in Salvador, I had been wrapping up extensive interviews with several travestis on their use of hormones. The contrast between the two contexts stimulated my thought process.

As part of their bodily transformation projects, travestis adopt both oral contraceptives and other methods, such as hormonal contraceptive injections that they obtain in informal ways. ${ }^{7}$ Hormones designed for physiological females are used according to specific ideas about sexuality and embodiment. Their use is founded on extremely detailed informal knowledge about the effects of hormones. Homemade hormone-therapies of these kinds often double or triple the recommended dosages for physiological females, thus producing very blatant effects. Such homemade treatments are particularly appreciated by the travestis for their effects in producing a feminine disposition and figure, in reducing bodily and facial hair, softening the voice and changing the quality of the skin. They are said by travestis to "quebrar o machão dentro da gente" (lit. "break the macho inside us"). Travestis frequently note their preference for injectable methods, sometimes referring to their milky color and quality. When oral contraceptives are used, they're generally crushed and mixed into

7 Although hormonal contraceptives are sold in packaging that specifies "by prescription only," in practice, only psychoactive medications are regulated in Brazilian pharmacies, which dispense all other substances freely. It is estimated that $75 \%$ of hormonal contraceptives are obtained directly from pharmacies, usually without a prescription (CEBRAP 2008). 
a milkshake, as travestis explain that if they swallow the pills whole, a paste-like deposit accumulates in their stomachs, causing nausea.

In the course of my interaction with ATRAS (lit. "behind"), the tongue-in-cheek acronym chosen by the Association of Travestis of Salvador, I was made aware of the political dimension of the struggle to obtain proper medical recognition and assistance.

The struggle was twofold. The first step was securing access to basic health care, as - given the high levels of prejudice towards travestis (who are regularly assimilated to prostitutes) and the disjunction between their physical appearance and the names on their identity documents - travestis often find themselves excluded from medical institutions. But their struggle also involved securing recognition of their specific medical needs and obtaining bormônio in the right dosage.

Until recently, there had been no medical provision in the Brazilian public health sector for "gender reassignment", i.e. treating people the medical profession designated as trans-. ATRAS leaders explained to me that although Brazilian travestis are actually different from trans-, Brazilian institutions modeled their position on those established in Europe and North America, where hormone therapy for gender reassignment is dispensed only to individuals wishing to undergo genital surgery. In 2009, the first outpatient service for travestis and transsexuals in Brazil was inaugurated in São Paulo (by the HIV/STD Reference Centre). Protocols in place include orientations and definitions of hormonal dosages for the development of so-called "secondary sexual characteristics." According to the official press release distributed by the center 6 months after its inauguration, 45\% of consultations were for hormonal therapies, $37 \%$ for sex-change surgery and $14 \%$ for the removal of industrial silicone implants. Manuela, one of ATRAS's leaders, explained to me in an interview:

For us, hormônio is a necessary evil. We have a female identity, we want to assume a female identity, but because of medical prejudice, hormonal therapies are only given to those who are preparing for surgery. We are fighting for the right to be feminine and to have access to the medical care we need in order to assume our identity, but without the obligation to undergo surgery, because we want to retain our penis. 
This question came up often during the weekly ATRAS meetings I attended. In one such meeting, the question of which medical specialist should be sought was raised. One travesti thought that a gynecologist would be most appropriate, given their knowledge of female hormones. She directed the question to me, but the chair cut in, exclaiming:

Are you crazy? What gynecologist? A gynecologist won't resolve anything! You don't have a uterus and ovaries, you have a prostate and testicles! What gynecologist is going to look after your prostate, you crazy drag queen?

This states the problem in its acute form, for in Salvador there is to this day no medical assistance for travestis, a fact that generates concerns about the massive, informal uses travestis make of pharmaceutical hormones. For ATRAS, this question has been singled out as one of political importance, a position that Manuela relayed to me in her commentary on travestis' refusal to submit to the binary gender norms that are reproduced even within bio-medical practice, according to which individuals wishing to effect changes in their sexual identity must do so entirely, or not at all. As a result, she explained, travestis make use of hormones in a dangerously unsupervised manner, raising substantial concerns over the long-term effects of this practice for their health. There is no epidemiological data available about the long-term effects of high-level doses of estrogen and/or progesterone on the male reproductive system.

My meeting with Manuela finished late that evening, and the next morning I walked into the first panel of the Gynecological Endocrinology Congress entitled: "The Use of Androgens in Gynecology" and presided by the highly controversial Elsimar Coutinho. ${ }^{8}$ The congress is a thoroughly official affair that is televised and attracts doctors from all over Brazil as well as from other Latin American countries. Panel members presented the different types of sub-dermal hormonal implants then available in Brazil, their

8 Coutinho, a doctor from Bahia, is popular with the media. He is known for his controversial opinions about connections between crime, race and overpopulation; about abortion and menstruation suppression, and for his biologized view of women's social role. 
composition and clinical uses. In their speeches, participants moved seamlessly from bio-chemistry issues like risk management for hormones' side effects to comments about the hormones' gendered characteristics, such as the self-confidence conferred by testosterone and the maternal instincts associated with progesterone... Coutinho's presentation on testosterone was immediately followed by the screening of a documentary made for Britain's Channel 4, entitled: "Testosterone: Are You Man Enough?" This documentary explores the uses made of testosterone by both men and women, not only as a treatment for declining libido but also, increasingly as a means of boosting assertiveness and self-confidence. Some extracts from the sound-track are reproduced here: ${ }^{9}$

Narrator: Imagine a drug that made you younger, richer, sexier, and all you had to do was rub it on. Believe the hype, and it already exists. [...] The testosterone revolution is coming. Will you be able to resist?

Dr Tedde Rinker, Anti-ageing specialist: [...] I call testosterone the yes hormone.

Narrator: Herthoghe is 45. He's been self-medicating testosterone for 15 years.[...] Herthoghe believes the male hormone could even help cut the divorce rate. He claims to have rescued relationships with testosterone alone.

Dr Thierry Herthoghe: I think that a lot of couples that want to divorce and to separate because of sex problems, or low love problems, are just hormone deficient persons.

Narrator: Testosterone isn't for men only. Its most dramatic effect is as an aphrodisiac for women. [...]

Dr Thierry Herthoghe: My wife takes testosterone, I have a sister who takes testosterone. Even my mother takes some small doses of testosterone. $[\ldots]$

9 A complete transcription of this documentary is available from:

http:/ /www.abc.net.au/cgi-

bin/common/printfriendly.pl?/catalyst/stories/s964127.htm (accessed on 17 Jan. 2011). 
Grace Ross: The fact that I take testosterone [...] has given me more insight on how men think, and I can understand why they think about sex all the time.

Narrator: Yes, testosterone makes you feel sexy, but it also makes you feel powerful.

Malcolm Whitehead, Gynecologist: I have patients who may have started testosterone because of poor sexual response, but they realize that the major benefit to them is the psychological boost they get in terms of being able to cope more effectively in a male-dominated environment.

Claude Mahaux: I take testosterone when I have to act like a man. It's amazing to see how you can be like a man for a few hours, and to stay a real woman after. [...] The world is so demanding to us, you know, we have a life in our - with our family, we have a life with our husband, work, leisure, sex, it's so many different activities, and testosterone gives you maybe the power and energy to put your limits in all these little domains. [...]

Narrator: Until now, extra testosterone has been a luxury for the rich and powerful. Not any more. US prescriptions for the drug are doubling each year, and like Viagra, a booming black market makes it readily available. [...] Once, natural selection put a cap on natural hormone levels, now we can cheat biology.

This was a very surprising way to conclude a panel at a medical congress. During the question period that followed, Coutinho stood up, microphone in hand, and addressed the overflowing hall of gynecologists, transforming what might have been a more scientifically informed discussion into a statement about "the patient's right to choose." Such a formulation clearly reveals the tension between the logic of choice and the logic of care in health. ${ }^{10}$

"Woman," Coutinho proclaimed, "can now be dona (mistress) of her own body, and no longer needs to be subjected to the 'rules' established by society." Coming from an advocate of menstrual suppression, the statement was a deliberate pun, since the word rules also means "period" in the sense of "menstruation", in Portuguese. Continuing his diatribe, he related how his friend Marta Suplicy (the former mayor of the megalopolis of São Paulo, who had recently remarried) had come to him to ask for something to "spice up" her

10 Mol 2008. 
honeymoon. After a pause for effect, frowning and cocking his head to the side, he asked his partly enchanted, partly skeptical audience:

What was I supposed to do? Refuse to give her testosterone on the basis of a few potential and ill-explored risks? Tell her, 'No, Marta, act your age! What is a woman of your age doing taking on the largest city in Latin America? Go home to your grandchildren and your knitting. And what's all this about a honeymoon? You're too old for that nonsense!' Is that what you would have me tell her? No, my friends, I won't do that! If that's your attitude, fine, but don't tell your patients that it can't be done, tell them that you won't do it, and send them to us instead!

Thus, by examining hormone use, we see how, above and beyond the usual representation of sexual dimorphism (feminine/masculine) that they represent, something else appears. Androgens have in fact been adopted without noticeable difficulty; both by doctors, who prescribe them, and by women, who use them to create new forms of femininity. With testosterone, women can acquire the power of men and yet remain "real women" - or even superwomen. Super-desiring and desirable. And perhaps above all, super-productive. Yet, although the absorption of "masculine substances" into women's bodies has been medically and socially legitimized, the opposite is not true.

Having seen that the attribution of sexual characteristics can become partially exogenous to the body through the production of hormones in the form of pharmaceutical products, I propose to analyze the way in which these hormones have come to be understood as a kind of substance that circulates between bodies, producing gendering effects.

\section{The fluid properties of hormonio}

The meaning of the term hormônio is not fully captured by the English term hormone. Hormônio occupies a semantic gap that was opened by humoral ideas about bodily capacities, which derived from $17^{\text {th }}$ century versions of Hippocratic medicine brought to colonial Brazil by European physicians. This humoral understanding of bodies is based on ideas about the flow and transmutability of bodily substances. The common usage, in Bahia, of the singular form hormônio - gives it a fluid, homogenous quality that is absent in the plural form. Further, the most commonly reported side effects of 
hormônio are weight-gain and swelling (inchaço); this reinforces the idea of hormonio as a physical substance that saturates the body's cavities. In this representation, hormônio is seen essentially as a substance rather than as a chemical entity, as one might expect in such a highly medicalized context.

These terminology issues and their semantic content emerged with particular clarity in the answers received to the question about hormones in my question guide. "If you had to explain to someone how hormones work, what would you say?" My interview subjects were often thrown by that question, or else they would answer in terms of the hormones' clinical effects, like weight gain or headaches.

The first example came from Antonia, a nurse who works in a plastic-surgery clinic. Antonia, who has been using Depo-Provera, a quarterly contraceptive injection that has allowed her to suppress her period for 10 years, answered my question with reference to the effects Depo-Provera had in her body:

A lot of people think you get fat when you take hormônio. But I didn't notice anything, no change whatsoever. Actually, my life improved. There were no disadvantages to not getting my period. Except for the fact that it took me three years to get pregnant because of the hormônio... But I don't know anything about how hormônio works. I can tell you about the advantages of hormônio, but I haven't got a clue about how it works! I'm not really that interested in that sort of thing.

Rosedete is a 27 -year-old patient I met in the medical center where she was trying to have a contraceptive implant removed. It had been inserted by a male gynecologist who hadn't explained that it was a hormonal method. She said that all he told her was:

It's just a thing that goes under your skin [...]. I didn't realize it was hormônio until I noticed the effects. As the months went by, I started putting on a lot of weight. Since I stopped Depo-Provera because of the weight gain, how could that doctor have thought I'd want an implant if I had known it was hormônio? When I went back to see him he said I should try "shutting my mouth" because food, not bormônio, is what makes people fat. I know it's the hormônio because I didn't start gaining weight until I started using hormonio. I don't know how hormônio affects my body, but I sure can see that it's having an effect! 
Tatiana is a journalist. She answered my question about hormones by talking about the sense of pleasure and relief she gets from the flux of menstrual blood during her periods. Moving seamlessly from a detailed description of the experience of monthly bleeding to hormônio, she said:

I wanted to find out more about that hormonal thing, so I typed "pineal gland" into Google. Apparently it's a portal of connections.

When I repeated my question a little more insistently, she replied:

I don't know anything about hormônio! [...] I don't even know what those bicbinhos (little things/animals) are called!

Similarly, in the answer I got from Nanda, a communications consultant, the connection between hormônio and the relief she gets from monthly bleeding is also quite explicit:

I see the function of hormônio in women - the oscillation of hormônio - as the antithesis of the rational. It's kind of a weird way of looking at it! But the hormonal person is completely surrendered to her body and under its sway. She does things she doesn't want to do rationally; she loses control. Woman is a being full of hormônio, and she has to deal with that. With menstruation, I feel renewed. I don't think it's dirty, I feel like it's a cleansing, an evacuation. It comes out because it has to come out, you know? Why accumulate all that in your body? But all that doesn't sound very scientific, does it!

The association these women make between hormônio, blood and the relief afforded by menstrual bleeding is striking. It came up repeatedly over the course of my research in Bahia and led to more in-depth questions about the local notion of substance. Why did my questions about hormones trigger so many answers about blood?

\section{Hormônio, blood and substance}

These different examples show that in Bahia, hormônio is sometimes understood as a sort of substance, not unlike blood itself in certain respects. Like blood, hormônio has both specific physiological features and the capacity to accumulate in the body, lodging in its cavities and producing swelling. In order to better understand the local conceptions of blood, and following several people's advice, I contacted a blood-donation center and explained my research to the 
staff. They opened their doors to me far more easily that I would have thought; and the health professionals had endless stories to tell about the population's ideas about blood. ${ }^{11}$ The main manner in which hormônio is understood to act on blood is through its effects on the flow of menstrual blood. In Bahia, many women have adopted hormonal contraceptives, whose advantages are frequently touted in the media. But these products lead to suppression of the menstrual cycles (which is presented as one of their advantages), and many women eventually give the products up because they are worried about the blood accumulating inside their bodies. For instance, Joseneide, a young blood donor, explained that she had been diagnosed with a fibroma. Since she uses Depo-Provera, she interprets the appearance of the fibroma as a sign that hormonio accumulated in her uterus, forming the growth. Doctors in Brazil will often perform hysterectomies in cases like that, and the operation is in great demand. But in this case, the doctor who examined her at her neighborhood health clinic prescribed a hormonal treatment to shrink the fibroma. Joseneide is particularly skeptical about the doctor's prescription, given that, in her understanding, hormônio accumulation is what caused the fibroma in the first place. She is actively seeking a doctor who would be willing to perform a hysterectomy, and she jokes that, for any woman who has "had all her kids," the uterus is descartável (disposable), an expression that I heard a lot in Bahia. Given that I was asked to wear a white lab coat (required in order to have access to the medical centers where my research took place), Joseneide asked me if I could find a doctor who would be willing to operate on her.

The chain of associations that Joseneide made from hormonal contraception to a prophylactic hysterectomy and the iatrogenic origin of her fibroma suggests that the impressive popularity of surgical procedures in Brazil can be interpreted in terms of notions about the local conceptualizations of humoral accumulation. Joseneide's account revealed the associations that are commonly made between fibromas and the notion of a pathological accumulation of blood related to the retention of the flow of

11 Sanabria 2011. 
menstrual blood and the use of hormônio. Her case is particularly striking, because it reveals that the body is understood as a kind of recipient that can be filled and purged. These actions in turn have implications for the body's ontological status.

The anthropological literature on substance is vast and has a complex historiography ${ }^{12}$. For present purposes, I would simply like to draw attention to the way in which, in a range of contexts, transmutations in bodily substances such as blood, semen, mother's milk and menstrual blood are understood to produce differences in persons' sexual capacities or physical attributes. The analogies or asymmetrical evaluations made between different bodily substances are at the basis of a number of gender-differentiation systems ${ }^{13}$. These models are founded on an understanding that - while they are associated with one or the other gender - bodily substances are transformable, and exchangeable between bodies. For the Samo of Burkina Faso - as Françoise Héritier described them in her work semen is understood to turn into blood in a woman's body: blood that she loses during her period. Maurice Godelier accounts for masculine domination among the Baruya partly through the conceptions they have about bodily substances. ${ }^{14} \mathrm{He}$ argues that for the Baruya, breast milk is in fact understood to be semen that has been transformed within the mother's body. All substances thus have a masculine origin. Whereas Strathern argues that this asymmetry can be considered in a different light. ${ }^{15}$ In her analysis of Melanesian exchanges, gender is not an attribute of a body but rather of relations which involve the detachment, elicitation or exchange of substances. Carsten has shown how the term "substance" has been used to achieve quite different goals in anthropological kinship analyses. This polysemy in part explains how the term substance was effectively used to signify such divergent meanings. ${ }^{16}$

12 See Carsten 2004.

13 Particularly in the ones described by Gregor \& Tuzin 2001; Héritier 1996; Mosko 1985.

14 Godelier 1982.

15 Strathern 1988.

16 Carsten 2001. For Schneider (1968) substances, particularly blood, stand for that which is "unalterable and indissoluble." On the other hand, in Indian and 


\section{"One-sex" thinking in a "two-sex" world}

The most explicit interpretations of the relationship between hormônio's substantive properties and issues of sex and gender come from the research I did with the travestis. During one of the weekly meetings I attended, the head of ATRAS asked if the members present would be willing to talk about their experiences with different types of hormônio and their effects. The discussion that followed was very lively. Several travestis spoke of their experience with these drugs in terms of feeling "cheia (full)" of hormonio. Others pointed out that when they injected a lot of it, their bodies were so full of hormonio that it oozed out at the spot where they had injected it, as if they were overflowing with it. A similar example of hormônio's substantive property is given by Kulick in his book Travesti:

...travestis also believe think that it is unwise for them to ejaculate while they are taking hormones, because they think that hormones are expelled from the body in that way. Each ejaculation, therefore, means progressively smaller breasts ${ }^{17}$.

During one particularly memorable ATRAS meeting, a lively debate arose regarding the use of different brands of hormones to "give birth" to breasts (fazer nacer o peito). Travestis' breasts are often the product of repeated injections of hormones, which are used prior to the "pumping" of liquid industrial silicone, as they are said to shape the body from the inside, creating a space that can later be filled with silicone.

Tensions surrounding issues of identity politics, which I had not at first grasped, were latent within this debate about using hormones to "beget" breasts. Marlene, one member of the group, stated that "My chest is (e) Depo-Provera," a comment that echoed the Brazilian idea that someone's chest is silicone ("seu peito é silicone"). This formulation reinforces the idea that hormonio is a material that settles in the body, filling up space according to the laws of its own, specific "fluid mechanics." Tensions arose when Marlene explained that when she was injecting Depo regularly to give birth to her breasts, her body

Melanesian ethnography, the term was adopted to speak of the mutability and fluidity underpinning notions of the person.

17 Kulick 1998 : 66 
was so saturated with hormonio that her breasts had oozed milk. Drawing a pointy little breast out from under her top, she exclaimed: "I was so full of hormônio that milk was dripping from this breast." At that point, another, particularly aggressive participant turned to her and snapped, "That wasn't milk, you poor drag queen, that was sperm!"

Marlene, with whom I subsequently carried out an extensive interview, later gave me the context within which to understand this exchange of words. She explained that, unlike the other members of ATRAS, she thought of herself as a trans- rather than a travesti, so she was stigmatized at meetings. Unlike the travestis, whom she described as vulgar and scandalous, she dressed in smart office apparel. Her scathing challenger, who "lives and works in the street," is provocative and aggressive. The challenge to Marlene's assertion to (full) femininity - breasts dripping with milk - through the reassertion of her concomitant masculinity - emblematized by sperm - illustrates the way in which hormonio is adopted to speak of bodily capacities to transmute fluids. In addition, in this altercation, the religious tenor of the story - which evokes representations of the "Nursing Madonna" or "Madonna Squirting Milk" that are so frequent in Latin American Catholicism - shouldn't be overlooked. It reveals the potency of religious imagery in defining gender norms. In alluding to that image, Marlene claims as her own a specific representation of the feminine (maternal gentle, passive) that is at odds with the highly sexualized one that most of the other participants at the ATRAS meeting aspire to.

The possibility of synthesizing hormones and making them available as pharmaceutical products creates a disjunction between sexed substance and sexed body. I am analyzing here the way in which this disjunction leads to a regulation of the use of diverse synthetic hormones depending on the patient's sexual identity. This regulation becomes more complex when prescribed or informally adopted hormonal regimens trouble gender norms. In those cases, it can be observed that the pharmacological provision of "gendered" hormones into the body is subject to specific regulation. We have seen that the use of testosterone in therapies prescribed for women posed fewer problems than did the use of estrogen for men. By 
describing the experimentation that sexual identity is submitted to in Salvador through the lens of the reorientation of the flow of sexual substances, I am querying the issue of those sexual identities that are caught between the sexual dichotomies still widely operational within bio-medicine. This notion of a re-channeling of sexual substances is further illustrated by a final ethnographic example that claims to reveal a highly idiosyncratic Judeo-Christian origin for the idea of the substance transmutation. Referring to the importance of estrogen in clinical practice, one locally prominent female gynecologist (who is published in international reproductive journals) made explicit reference to the Bible when she addressed the Congress of Endocrinological Gynecology:

Estradiol is the feminine soul; estradiol is what allows us to attract males. It's a fundamental hormônio. And I will add that without estradiol, testosterone is nothing! Just as Eve came out of Adam's rib, estradiol comes out of testosterone. It's such a physiological hormone that no one pays any attention to it. We women have had our period of reclusion, we were our husband's property; then we had to become macho (male). Now we can be more competitive: mothers, professionals and feminine. Women today want to improve their sex lives and their self-confidence. [...] So E2 lets women get to where they want to be. It's a very old hormone, but it's totally modern. It combines femininity and activity.

Aside from the serious implications that a representation like that has on the hierarchical evaluation of hormones and the identities they produce, this statement provides a view of the body and of sexual identity that fits perfectly into what Laqueur ${ }^{18}$ called the "one-sex" body. In his history of the "making of sex" (or of the two sexes), Laqueur argues that before the Enlightenment, the bodily bases of gender were understood analogically, and the difference between the sexes wasn't thought of as grounded in biology. According to Laqueur, during that period, gender derived from a single, paradigmatic non-sexed body, and bodily facts did not lend themselves to the same kind of ideological investment as they did with the advent of the new, empirically based anatomy. His distinction is useful from a heuristic point of view, insofar as it

18 Laqueur 1990. 
reminds us that the categories masculine/feminine have a history, ${ }^{19}$ and also precisely because it provides a frame that reveals more clearly the phenomena that do not fit into it neatly. Hormônio, in the Bahian context, clearly troubles the binary version of sex, revealing to what extent regulatory and legal practices ascribe the two-sex model as normative.

In addition, I would point out that, in the Bahian context, the lack of regulation of the medical and pharmaceutical sectors leaves the door open to the possibility of unauthorized experimentation (by both doctors and patients) and usages that would be impossible in other national contexts. In 2010, a series of articles in the press revealed that in many Brazilian gyms, women were choosing to use contraceptive implants containing testosterone in order to "bulk up" their muscle mass, get the most out of their athletic efforts, and "increase their libido." Although they do address the issue with a critical eye, the articles that are passed around about the chipadas as they're called - women, who have an integrated circuit implanted provide plenty of details about the existing methods and the doctors who prescribe them. So testosterone isn't considered to be masculine per se, even if it produces masculinizing effects that can nevertheless be adopted in the production of new forms of femininity. Thus the sexualization of the body isn't seen as something entirely immutable, and the way Brazilians use hormones suggests that despite the fact that it's supposedly dominant, we are not completely in thrall to the "two-sex" model.

\section{Reassembling sex}

An ethnographic analysis of hormonal practices in Bahia allows us to highlight the way in which hormones are involved in the materialization of sex. It offers a partial answer to the issue raised by Butler in Bodies That Matter, when she asks, "How do tacit normative criteria form the matter of bodies?"20. Butler's emphasis on the performative aspects of gender in Gender Trouble was critiqued for

19 His model has been the subject of a great deal of criticism, see for example Park \& Nye 1991.

20 Butler 2009. 
supposedly disavowing the constraints imposed by "sex" and the body's materiality. So her following book, Bodies That Matter, specifically attends to the ways in which norms materialize the body by showing that the concept of materiality is itself sexed and by describing "sex" as a process of materialization. The many biological and social elements that are required to constitute "sex", (and not just "gender") efforts need to be painstakingly deployed to reassemble these with the consistency that makes us blind to the manufactured aspects of "sex". This endless constitutional effort offers multiple opportunities for unexpected elements to slip in, and thus to trouble the reiteration of sexual identities. Although hormones widely continue to be sexed in both scientific practice and popular thinking within a binary model, the Bahian ethnographic materials presented here imply ways in which the reiteration of "sex" through hormonal practices is subject to the kinds of instabilities and excesses that Butler calls attention to.

The Bahian notions of hormônio also show that the body is not seen as a fixed basis for identity, which must partially explain the ease with which medical practices are adopted to transform the body. That has specific implications for "sexual identity" insofar as the conceptualization of hormones as a substance reveals the relative plasticity of the sex/gender relationship. What is generally understood to constitute "sexual identity" (specific bodily characteristics) or gender (appearance or behavior) is partially dissociable from the body or associable to another body through the use of gels, injections or drugs that bestow new identities. Like blood, hormônio obeys a hydraulic logic in local understanding. Interventions performed on the body affect the quality or modify the flow of these fluids, demonstrating an understanding of the body as inherently malleable. Social norms are what determine or legitimize some aspects of gender bending, at the expense of others. It is in this sense that I propose that both prescribed and informal uses of these pharmacotherapies enact a troubling, not only of sex/gender, but also of the distinction between these two terms.

Translated [in consultation with the author] by Regan Kramer 


\section{Bibliography}

ButLER Judith, Gender Trouble: Feminism and the Subversion of Identity, New York, Routledge, 1990.

—, 1993, Bodies That Matter: on the Discursive Limits of "Sex", New York, Routledge.

CARSTEN Janet, 2001, "Substantivism, Antisubstantivism, and Antiantisubstantivism," in Sarah FrANKLIN \& Susan MCKINNON (eds), Relative Values: Reconfiguring Kinship Studies, Durham, Duke University Press.

—, 2004, After Kinship, Cambridge, Cambridge University Press.

CEBRAP, 2008, Pesquisa Nacional de Demografia e Saúde da Criaça e da Mulher - PNDS 2006: Relatório Final. Brasília, Ministério da Saúde.

http://bvsms.saude.gov.br/bvs/pnds/img/relatorio final pnds2006.pdf

Fausto-Sterling Anne, 2000 Sexing the Body Gender Politics and the Construction of Sexuality, New York, Basis Books, 2000.

Godelier Maurice, 1982, La production des grands hommes, Paris, Flammarion.

Gregor Thomas \& Donald Tuzin, 2001, Gender in Amazonia and Melanesia, Berkeley, University of California Press.

Héritier Françoise, 1996, Masculin, Féminin. La pensée de la différence, Paris, O. Jacob.

Kulick Don, 1998, Travesti: Sex, Gender, and Culture among Brazilian Transgendered Prostitutes, Chicago, The University of Chicago Press.

LAQueur Thomas, 1990, Making Sex: Body and Gender from the Greeks to Freud, Cambridge, Mass., Harvard University Press.

Mol Annemarie, 2008, The Logic of Care: Health and the Problem of Patient Choice, Abingdon, Routledge.

Mosko Mark, 1985, Quadripartite Structures. Categories, Relations, and Homologies in Bush Mekeo Culture, Cambridge, Cambridge University Press.

Oudshoorn Nelly, 1994, Beyond the Natural Body: Archeology of Sex Hormons, London Routledge.

PARK Katherine \& Robert NyE, 1991 "Destiny is Anatomy"”'”, The New Republic, 3970 , p. 53-57.

SANABRia Emilia, 2011, « Pourquoi saigner? Menstruations, dons de sang et équilibre corporel au Brésil », Terrain, 56, p. 42-57.

SCHNeIDER David, 1980 (1968, 1re éd.), American Kinship: A Cultural Account, Chicago, University of Chicago Press.

STRATHERn Marilyn, 1988, The Gender of the Gift, Berkeley, University of California Press. 